\title{
Formation of All-Carbon Quaternary Centers by Copper-Catalyzed Asymmetric Conjugate Addition
}

\author{
Alexandre Alexakis*, Magali Vuagnoux-d'Augustin, David Martin, Stefan Kehrli, Laetitia Palais, \\ Hélène Hénon, and Christine Hawner
}

\begin{abstract}
This mini-review deals with a special, and challenging, aspect of the asymmetric conjugate addition: the formation of all-carbon quaternary centers by reaction with Michael acceptors bearing a polysubstituted unsaturation. Only copper catalysts allow this transformation, along with a careful choice of primary organometallics and chiral ligand. The resulting adducts are useful intermediates for the synthesis of more complex natural products.
\end{abstract}

Keywords: Aluminium · Asymmetry · Catalysis · Conjugate addition · Copper · Magnesium · Zinc

\section{Introduction}

The conjugate addition reaction is one of the fundamental transformations in organic synthesis.[1] The introduction of hard, nonstabilized, nucleophiles is best achieved with organocopper reagents, or copper salts catalyzing the reaction of a primary organometallic, such as $\mathrm{Mg}, \mathrm{Zn}, \mathrm{Al}$ reagents. ${ }^{[2]}$ The asymmetric version of this reaction has a long history, but the true breakthrough came in the late 1990s. ${ }^{[3]}$ It was first found that $\mathrm{R}_{2} \mathrm{Zn}$ reagents were the most appropriate, and that tris-heterosubstituted phosphorus ligands were the best ones. In parallel, a rhodium-catalyzed version was developed, equally efficient, and complementary to the $\mathrm{Cu}$-catalyzed one. ${ }^{[4]}$ With $\mathrm{Cu}$, alkyl groups (even functionalized ones) were transferred, whereas with $\mathrm{Rh}$, only aryl and alkenyl groups were transferred, via their boronic acids. Over the years, the $\mathrm{Cu}$-catalyzed asymmetric conjugate addition (ACA) was successfully applied to many different Michael acceptors, such as cyclic ${ }^{[5-9]}$ and acyclic enones, ${ }^{[10,11]}$ lactones ${ }^{[12,13]}$ or lactames, ${ }^{[14]}$ nitro-olefins, ${ }^{[15-18]}$ amides $^{[19]}$ and malonates. ${ }^{[20-22]}$ However, whatever the Michael acceptor, all attempts on substrates bearing a $\beta$-disubstituted double bond lacked reactivity, probably for steric reasons (Scheme 1). The same statement applies for the Rh-catalyzed version. This is a serious drawback because the creation of enantioenriched all-carbon quaternary centers is still a synthetic challenge. ${ }^{[23,24]}$ We shall see how this problem was handled, and partially solved, through the different organometallics that were used.

\section{Diorganozinc Reagents}

Diorganozinc reagents were shown to be the first and most efficient primary organometallics for the $\mathrm{Cu}$-catalyzed ACA reaction. ${ }^{[3]}$ However, they lack reactivity when confronted with sterically hindered substrates. A first approach, by the Hoveyda group, was to use the most reactive substrates known for this conjugate addition, that is nitro-alkenes (Scheme 2). ${ }^{[25]}$ Several other examples show the generality of this reaction, even with the less reactive $\mathrm{Me}_{2} \mathrm{Zn}$, although the temperature has to be increased to $0{ }^{\circ} \mathrm{C}$.

With unsaturated ketones, the carbonyl group is a less electron-withdrawing group than the nitro functionality. Thus, for cyclic enones, such as 3-methyl cyclo-
${ }^{*}$ Correspondence: Prof. Dr. A. Alexakis Department of Organic Chemistry

University of Geneva

Quai Ernest Ansermet 30

$\mathrm{CH}-1211$ Geneva 4

Tel.: + 41223796522

Fax: + 41223793215

E-mail: alexandre.alexakis@chiorg.unige.ch

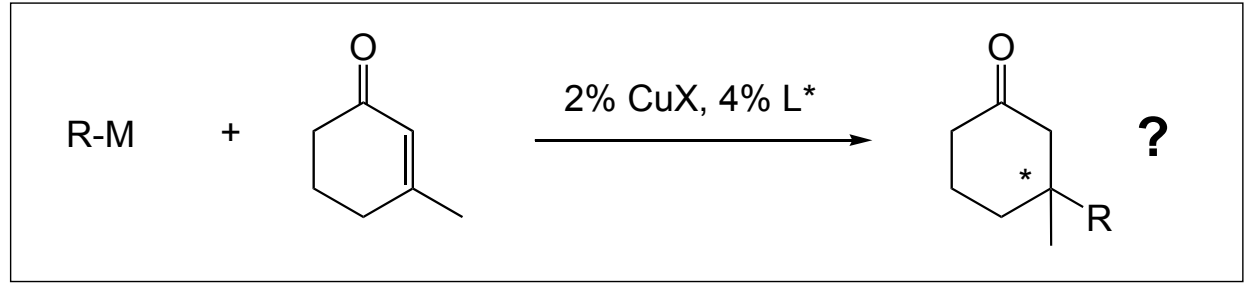

Scheme 1. Conjugate addition to $\beta$-disubstituted enones<smiles>C/C(=C/[N+](=O)[O-])c1ccccc1</smiles>

$$
\underset{\text { toluene, }-78^{\circ} \mathrm{C}, 24 \mathrm{~h}}{\stackrel{3 \mathrm{Et}_{2} \mathrm{Zn}, 2 \% \text { CuOTf, } 4 \% \mathrm{~L}^{*}}{\longrightarrow}}
$$<smiles>CC[C@@](C)(C[N+](=O)[O-])c1ccccc1</smiles>

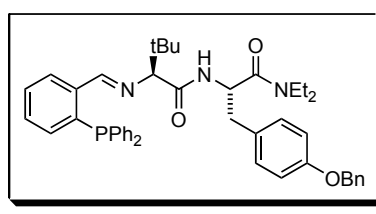

Scheme 2. Addition to $\beta$-disubstituted nitro-alkene 

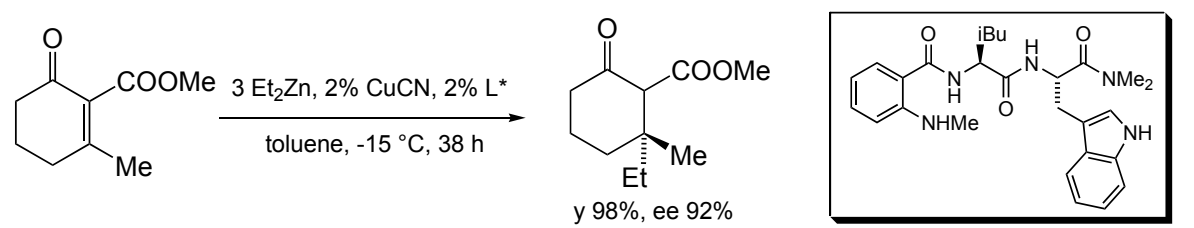

Scheme 3. Addition to doubly activated enones

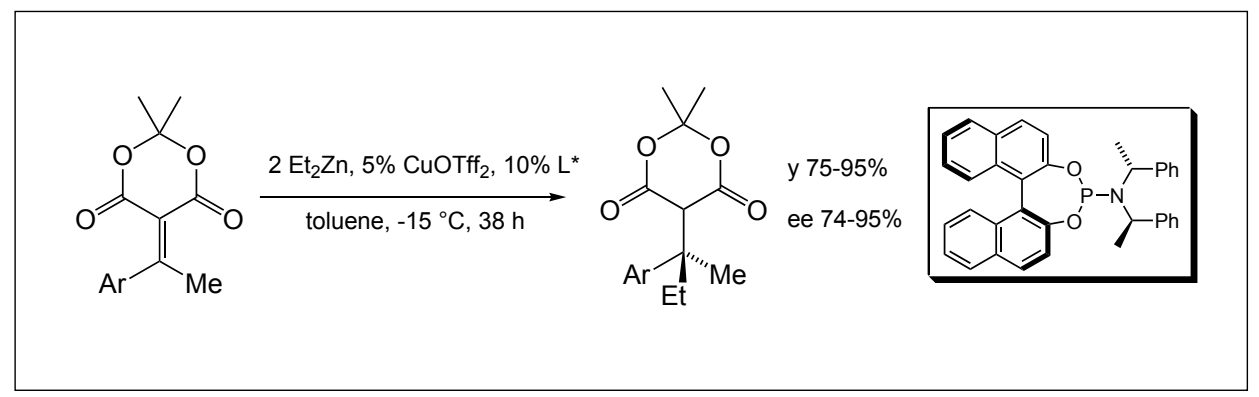

Scheme 4. Addition to alkylidene malonates
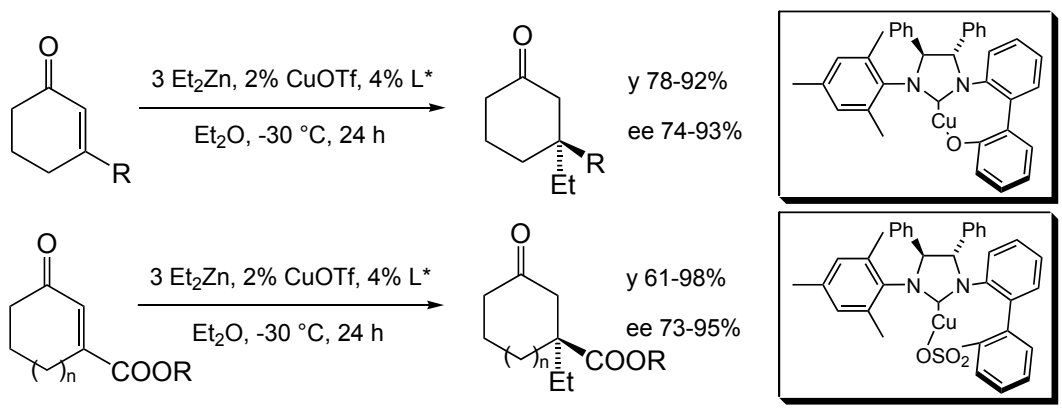

Scheme 5. Addition to 3-alkyl cyclohexenones

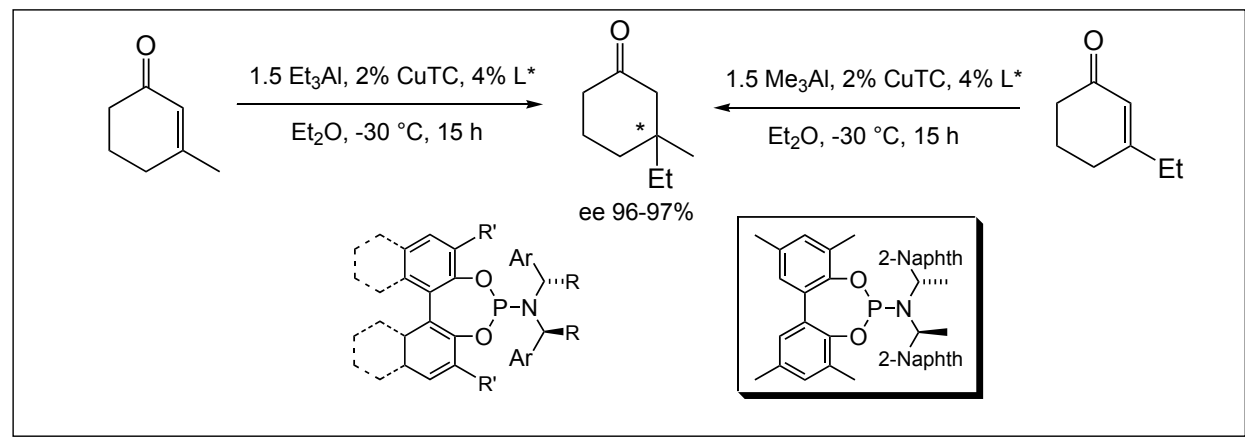

Scheme 6. Addition of $\mathrm{R}_{3} \mathrm{Al}$ to 3-alkyl cyclohexenones

hexenone, Hoveyda added an additional activating group, which now allows the reaction to take place. ${ }^{[26]}$ Thus a double activation seems to be a good 'trick' to enhance the reactivity of such substrates. However, the ligand had to be changed, and after screening 90 ligands, one was found that affords excellent yield and enantioselectivity (Scheme 3). This problem emphasizes the importance of the ligand in all these reactions. The carbomethoxy group could be subsequently removed, or exploited for additional transformations, in good yield.

The same strategy was followed, for alkylidene malonates, by Fillion and Wilsily.[27] Here again, two activating groups are needed. Not only that, but the malonate derivative had to be from Meldrum's acid in order to get the reaction takes place. Even then, the poorly reactive $\mathrm{Me}_{2} \mathrm{Zn}$ could not be transferred. Otherwise, the yields and enantioselectivities are good to excellent (Scheme 4).

As stressed above, the nature of the chiral ligand plays a fundamental role on the reactivity of the organometallic species. Hoveyda and coworkers found that with diaminocarbene ligands (N-heterocyclic carbenes or NHCs) the rate enhancement allowed, now, the reaction to proceed without double activation. The precursor of the $\mathrm{Cu}$ carbene was the dimeric Ag carbene, easier to handle. Thus the addition could take place on simple 3-alkyl substituted cyclohexenones with excellent yields and enantioselectivities (Scheme 5). [28]

Again, the poorly reactive $\mathrm{Me}_{2} \mathrm{Zn}$ could not be added. However, it was shown that diphenyl zinc was reactive enough to be transferred. This is an important advancement, as the Rh catalyzed conjugate addition is not operative with these polysubstituted Michael acceptors. ${ }^{4]}$ Strangely, although high, the phenyl group affords the opposite enantioselectivity with the same chiral ligand! When the 3-substituent is a carbalkoxy group, this double activation allows the reaction of both $\mathrm{Me}$ and $\mathrm{Ph}$ groups, in addition to normal $\mathrm{R}_{2} \mathrm{Zn}$. ${ }^{[29]}$

\section{Triorganoaluminium Reagents}

A different strategy was followed by Alexakis, who sought an enhancement of reactivity of the substrate through Lewis acid activation. It is well known that $\mathrm{Al}$ salts are stronger Lewis acids than $\mathrm{Zn}$ salts. It is also well known that $\mathrm{R}_{3} \mathrm{Al}$ reagents are excellent primary organometallics for the copper-catalyzed asymmetric conjugate addition to cyclic [30,31] and acyclic enones, ${ }^{[32]}$ and nitro-olefins. ${ }^{[33,34]}$ It was found that both commercially available $\mathrm{Me}_{3} \mathrm{Al}$ and $\mathrm{Et}_{3} \mathrm{Al}$ are able to add to simple 3-alkyl cyclohexenones, with excellent yields and enantioselectivities. ${ }^{[35,36]}$ Among the variety of chiral ligands tested, a biphenol type phosphoramidite appeared to be the best. The two pathways shown in Scheme 6 afford opposite enantiomers, showing that the ligand imposes the same facial approach of the organometallic.

Of particular interest is the addition of $\mathrm{Me}_{3} \mathrm{Al}$, because it is the cheapest organometallic bearing the methyl group, and because this group is the most important from synthetic point of view. On the other hand 
<smiles>CCOC1=CC(=O)CCC1</smiles><smiles>[R]C1=CC(=O)CCC1</smiles><smiles>[R][C@]1([2H])CCCC(=O)C1</smiles><smiles>CCC1=CC(=O)CCC1</smiles>

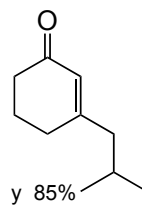

ee $96 \%$

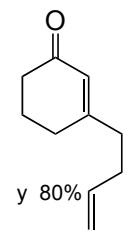

ee $95 \%$
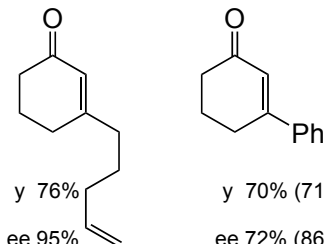

y $70 \%(71)$

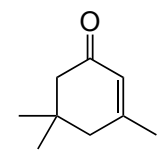

ee $72 \%(86)$

ee $97 \%$

Scheme 7. Addition of $\mathrm{Me}_{3} \mathrm{Al}$ to various 3-alkyl cyclohexenones

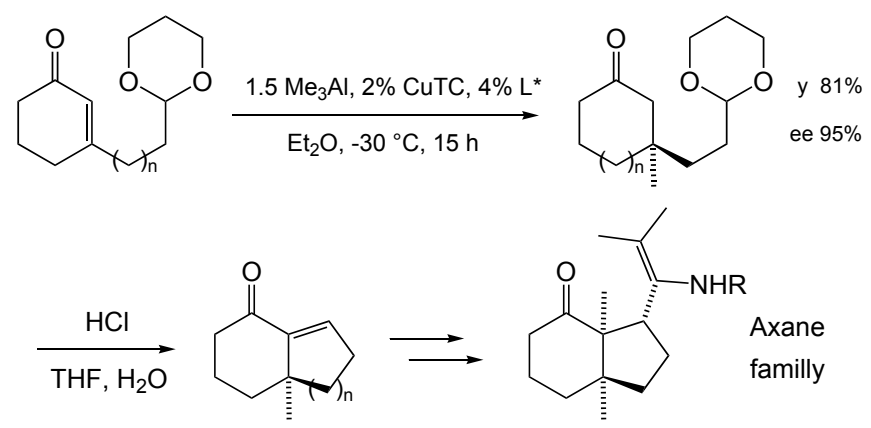

Scheme 8 Addition of $\mathrm{Me}_{3} \mathrm{Al}$ to functionalized 3-alkyl cyclohexenones

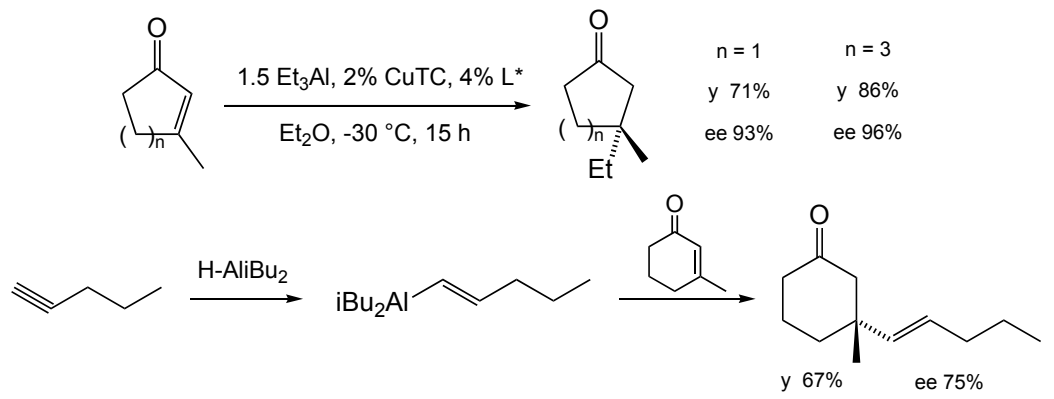

Scheme 9. Other additions of aluminium reagents

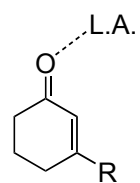

Lewis acid activation<smiles>[R]C1=C(C(C)=O)C(=O)CCC1</smiles>

Substrate activation

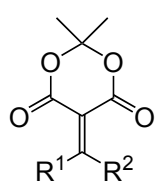

Fig. Strategies for the conjugate addition to polysubstituted enones

3-alkyl substituted cyclohexenones are readily available from commercial 3-ethoxy cyclohexenone (Scheme 7). Even very hindered enones, such as isophorone, are able to react (with $\mathrm{Et}_{3} \mathrm{Al}$ in this case). ${ }^{[36]}$ With the exception of 3-phenyl cyclohexenone, all the enantioselectivities are above $90 \%$. But even this difficult case could recently be improved to $86 \%$ by changing to our new SimplePhos ligand. ${ }^{[37]}$

The versatility of the methodology could be seen when functionalized substrates were used. Thus, an acetal functionality is tolerated. It allows, after deprotection and cyclisation, the introduction of an angular methyl group, found in so many natural products (Scheme 8$)$. ${ }^{[35,36]}$

More recently, the reaction has been extended to different ring sizes, five ${ }^{[38]}$ and seven, ${ }^{[36]}$ with equal success (Scheme 9). In addition, an alkenyl group could be introduced for the first time, ${ }^{[36]}$ by taking advantage of the preferred transferability of vinyl groups instead of alkyl ones. Thus, a simple hydroalumination of an alkyne, ${ }^{[39]}$ with DIBAL, allows the formation of the alkenyl aluminium reagent which is in situ reacted with the enone. Again, it should be emphasized that $\mathrm{Rh}$ catalysis is not operative with such an enone.

\section{Grignard Reagents}

Despite the extension to vinylic aluminium reagents, the commercial availability of $\mathrm{R}_{3} \mathrm{Al}$ is rather limited to few $\mathrm{R}$ groups. In order to expand this methodology to other nucleophilic R groups, Alexakis turned to a different strategy, i.e. a more nucleophilic primary organometallic (Fig.).

Grignard reagents are well known for their high reactivity in copper-catalyzed reaction, even on demanding substrates, such as trisubstituted enones. ${ }^{[40]}$ However, our attempts to use known ligands for this class of organometallics failed, either by poor regioselectivity (1,2 versus 1,4 addition) or by low enantioselectivity. Among the recently described ligands for the copper-catalyzed conjugate addition, the class of diaminocarbenes ${ }^{[41,42]}$ has emerged as a viable alternative to phosphorus-based ligands. When we tested the unprecedented combination of Grignard reagents and NHC as ligands in the conjugate addition, we found, after extensive screening, an appropriate ligand to obtain high enantioselectivities ${ }^{[43]}$ (Scheme $10)$.

Although the enantioselectivities are not as high as with $\mathrm{Al}$ and $\mathrm{Zn}$ reagents, the scope of the reaction is much wider. Various primary and secondary $\mathrm{R}$ groups, as well as a phenyl group, can be transferred without reactivity problems, with quantitative yields and good to excellent enantioselectivities. In a similar way, as before, the reaction occurs on variously substituted enones, including sterically hindered isophorone, with equal success.

\section{Conclusions and Outlook}

This overview shows that the asymmetric copper-catalyzed conjugate addition affords a viable methodology for the creation of all-carbon chiral quaternary centers. Until today, only the unique properties of copper, as compared to other 


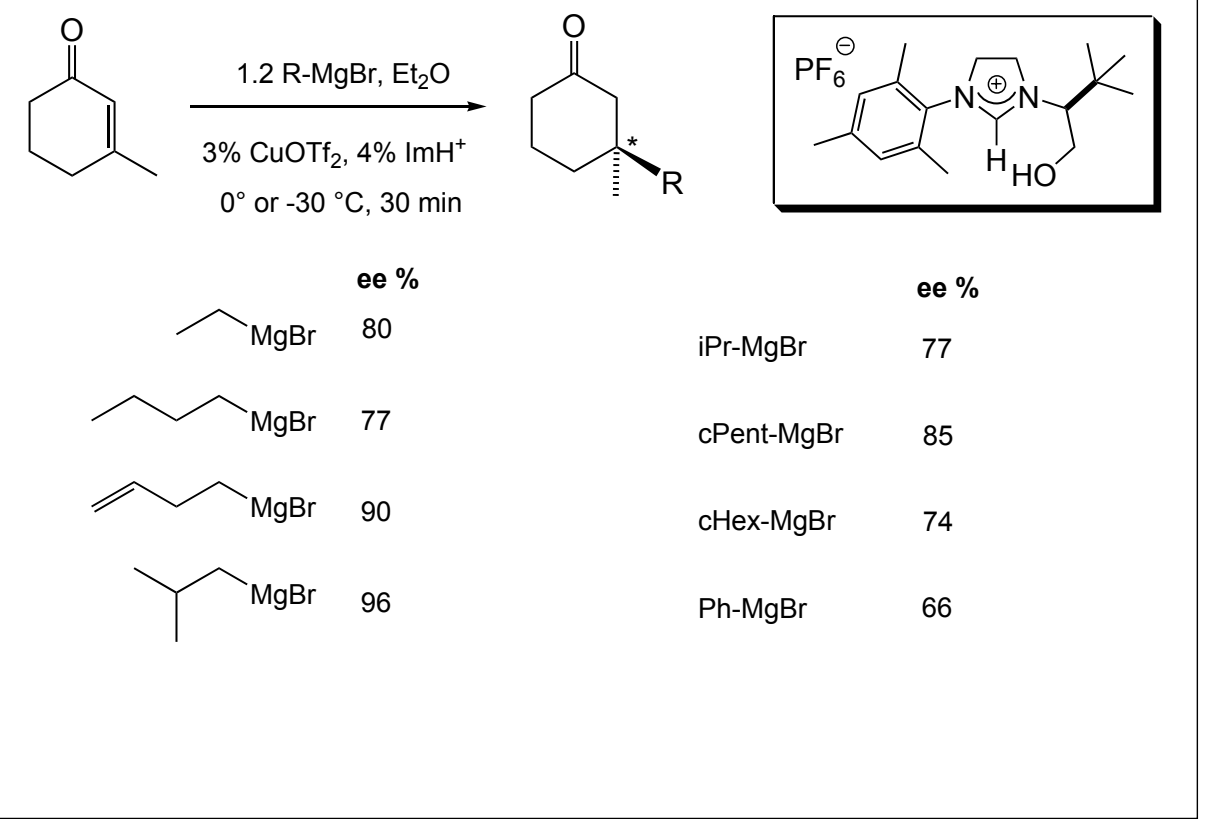

Scheme 10. Additions of Grignard reagents

transition metals, allows this challenging transformation. Comparing the different organometallics used, we can say that zinc reagents, although the least reactive, allow the addition of functionalized $\mathrm{R}$ group, whereas aluminium reagents are the best for the transfer of the Me group in terms of cost efficiency and enantioselectivity. However, Grignard reagents remain the ones with the greatest synthetic potential. They only need some improvement on the enantioselectivity, and we are working on it!

Received: February 4, 2008

[1] P. Perlmutter, 'Conjugate Addition Reaction in Organic Synthesis', Tetrahedron Organic Chemistry Series, no. 9, Pergamon Press, Oxford, 1992.

[2] For a review see: B. H. Lipshutz, S. Sengupta, Org. React. 1992, 41, 135.

[3] For a review see: A. Alexakis, C. Benhaim, Eur. J. Org. Chem. 2002, 3221.

[4] For a review see: T. Hayashi, T. K. Tamasaki, Chem. Rev. 2003, 103, 2829.

[5] A. Alexakis, D. Polet, S. Rosset, S. March, J. Org. Chem. 2004, 69, 5660.

[6] Z. Hua, V. C. Vassar, H. Choi, I. Ojima, Proc. Nat. Acad. Sci. 2004, 101, 5411.

[7] S. J. Degrado, H. Mizutani, A. H. Hoveyda, J. Am. Chem. Soc. 2001, 123, 755.

[8] L. A. Arnold, R. Imbos, A. Mandoli, A. H. M. de Vries, R. Naasz, B. L. Feringa, Tetrahedron 2000, 56, 2865.

[9] A. Alexakis, J. Burton, J. Vastra, C. Benhaim, X. Fournioux, A. van den Heuvel, J.-M. Levêque, F. Mazé, S. Rosset, Eur. J. Org. Chem. 2000, 4011.

[10] H. Mizutani, S. J. Degrado, A. H. Hoveyda, J. Am. Chem. Soc. 2002, 124, 779.
[11] A. Alexakis, C. Benhaim, S. Rosset, M. Humam, J. Am. Chem. Soc. 2002, 124, 5262.

[12] M. Yan, Z. Y. Zhou, A. S. C. Chan, Chem. Comm. 2000, 115.

[13] M. T. Reetz, A. Gosberg, D. Moulin, Tetrahedron Lett. 2002, 43, 1189.

[14] M. Pineschi, F. Del Moro, F. Gini, A. J. Minnaard, B. L. Feringa, Chem. Comm. 2004, 1244.

[15] A. Rimkus, N. Sewald, Synthesis 2004, 135.

[16] A. Duursma, A. J. Minnaard, B. L. Feringa, J. Am. Chem. Soc. 2003, 125, 3700.

[17] C. A. Luchaco-Cullis, A. H. Hoveyda, $J$. Am. Chem. Soc. 2002, 124, 8192.

[18] A. Alexakis, C. Benhaim, Org. Lett. 2000, 2, 2579.

[19] A. W. Hird, A. H. Hoveyda, Angew. Chem.,

[20] A. Alexakis, C. Benhaim, Tetrahedron: Asymmetry 2001, 12, 1151.

[21] T. Watanabe, T. F. Knöpfel, E. M. Carreira, Org. Lett. 2003, 5, 4557.

[22] J. Schuppan, A. J. Minnaard, B. L. Feringa, Chem. Comm. 2004, 792.

[23] B. M. Trost, C. Jiang, Synthesis 2006, 369.

[24] J. Christoffers, A. Baro, Adv. Synth. Catal. 2005, 347, 1473.

[25] F. Wu, D. M. Mampreian, A. H. Hoveyda, J. Am. Chem. Soc. 2005, 127, 4584.

[26] A. W. Hird, A. H. Hoveyda, J. Am. Chem. Soc. 2005, 127, 14988.

[27] E. Fillion, A. Wilsily, J. Am. Chem. Soc 2006, 128, 2774.

[28] K. S. Lee, M. K. Brown, A. W. Hird, A. H. Hoveyda, J. Am. Chem. Soc. 2006, 128, 7182.

[29] M. K. Brown, T. L. May, C. A. Baxter, A. H. Hoveyda, Angew. Chem., Int. Ed. 2007, 46, 1097. Int. Ed. 2003, 42, 1276.
[30] Y. Takemoto, S. Kuraoka, N. Hamaue, C. Iwata, Tetrahedron: Asymmetry 1996, 7, 993.

[31] L. Liang, A. S. C. Chan, Tetrahedron: Asymmetry 2002, 13, 1393.

[32] P. K. Fraser, S. Woodward, Chem. Eur. J. 2003, 9,776

[33] U. Eilitz, F. Lessmann, O. Seidelmann, V. Wendish, Tetrahedron: Asymmetry 2003 , 14, 3095.

[34] D. Polet, A. Alexakis, Tetrahedron Lett. 2005, 46, 1529.

[35] M. d'Augustin, L. Palais, A. Alexakis, Angew. Chem., Int. Ed. 2005, 44, 1376.

[36] M. Vuagnoux-d'Augustin, A. Alexakis, Chem. Eur. J. 2007, 13, 9647.

[37] L. Palais, I.S. Mikhel, C. Bournaud, L. Micouin, C. A. Falciola, M. Vuagnouxd'Augustin, S. Rosset, G. Bernardinelli, A. Alexakis, Angew. Chem., Int. Ed. 2007, 46, 7462.

[38] M. Vuagnoux-d'Augustin, A. Alexakis, Synlett 2007, 2057.

[39] For a review see: G. Zweifel, J. A. Miller, Org. React. 1984, 32, 375.

[40] N. Krause, in 'Modern Organocopper Chemistry', Wiley-VCH, Weinheim, 2001.

[41] A. Alexakis, C. L. Winn, F. Guillen, J. Pytkowicz, S. Roland, P. Mangeney, $A d v$. Synth. Cat. 2003, 345, 345.

[42] H. Clavier, L. Coutable, L. Toupet, J. C. Guillemin, M. Mauduit, J. Organomet. Chem. 2005, 690, 5237.

[43] D. Martin, S. Kehrli, M. d'Augustin, H. Clavier, M. Mauduit, A. Alexakis, J. Am. Chem. Soc. 2006, 128, 8416. 